\title{
Traps! An introduction to expanding thinking on persistent maladaptive states in pursuit of resilience
}

\author{
Keith Tidball $^{1} \cdot$ Niki Frantzeskaki ${ }^{2}$ Thomas Elmqvist $^{3}$
}

Received: 7 September 2016/Accepted: 14 September 2016/Published online: 6 October 2016

(C) Springer Japan 2016

\section{Introduction}

This special feature is the result of a long collaboration between Stockholm University and the Stockholm Resilience Center (SRC) and Cornell University's Department of Natural Resources, focused upon resilience as a key lens for biosphere-based sustainability science. Over the course of this collaboration, many other partners have been invited and have participated in the collaborations, mostly focused on the social questions within social-ecological systems' thinking and sustainability, especially (but not exclusively) the most social places of all, cities. For example, the Dutch Research Institute for Transitions has contributed to governance questions in urban contexts, focused on drivers and transformations in European cities. The collaborations, ostensibly products of the Urban Theme at SRC, evolved into an intense thought-collective named for the island where it emerged, Karklö, Sweden. In June of 2013 the Karklö Group rallied around the conceptualization of social-ecological traps as presented by the Stockholm Resilience Center's Research Insight $\# 5,{ }^{1}$ and followed Boonstra and de Boer's (2014) interrogation of the trap metaphor further into the realms of human action and social pattern and structure. In April of 2014 the group reconvened, this time in the Finger Lakes of Upstate New

Keith Tidball

kgtidball@cornell.edu

1 Department of Natural Resources, Cornell University, Ithaca, USA

2 Dutch Research Institute for Transitions, Erasmus University Rotterdam, Rotterdam, The Netherlands

3 Stockholm Resilience Center, Stockholm University, Stockholm, Sweden
York, at a farm on Cayuga Lake about an hour north of Cornell University, Ithaca. Here, the thinking about traps and social ramifications within a social-ecological systems framework gelled, and specific papers emerged, with a target of presentation at the Resilience 2014 conference in Montpelier, France. At the conclusion of a successful conference session featuring seven contributed papers, ${ }^{2}$ the group further focused and refined their thinking, resulting in the special feature before you now.

In this special feature we revisit the conceptualization of poverty and rigidity traps (Carpenter and Brock 2008) by considering how perceptions and perspectives of representations of stability landscapes can affect spatial and temporal micro- and macro-dynamics which shape the very landscapes that contain these traps. Transformations are radical changes of micro- and/or macro-dynamics that reshape the possibilities to escape these traps by reshaping/ changing the basins of attraction and the landscape. The popular practice of conceptualizing and then representing via heuristic models broader scale dynamics in the form of dynamic landscapes and smaller scale dynamics in the form of stability landscapes and basins of attraction raises new questions and new understanding of how the lenses with which we approach time and space dynamics impact the way SES develop and/or can be managed over time. In this thinking, institutions and how they operate in relation to micro- and macro-dynamics resemble some archetypical behavioral patterns conceptualized as institutional traps,

\footnotetext{
$\overline{1}$ http://www.stockholmresilience.org/download/18.3e9bddec 1373 daf16fa43c/INsights_Social-ecological+traps_111108-2.pdf.

2 Resilience 2014 Session 56 "Tips or traps? Advancing Understanding to Steer Clear of Impoverishment Traps and Tipping Points"- see http://www.slideshare.net/kgtidball/session-56-tipsortraps.
} 
which are related to the more commonly referenced rigidity and poverty traps.

In this special feature, we ask "How might the ways scholars conceptualize and depict system properties and states influence either the managers of these systems or the systems themselves?" and "Could new and novel ways of characterizing and understanding as well as employing the notion of traps help us answer the first question posed?" To interrogate these possibilities, we revisit the conceptualization of poverty and rigidity traps as described by Carpenter and Brock (2008) and institutional traps as conceived of by Polterovich (2008) by speculating about how representations of traps within stability landscapes by social-ecological systems (SES) resilience scholars might potentially affect spatial and temporal micro- and macrodynamics, which could sometimes influence or shape the very landscapes that feature these traps. The increasingly common practice of conceptualizing and then representing via heuristic models broader scale dynamics in the form of dynamic landscapes and smaller scale dynamics in the form of stability landscapes and basins of attraction raises new questions regarding how the lenses with which scholars approach time and space dynamics relative to traps impact the way SES develop and/or can be managed over time. In this thinking, some structures within socialecological systems and how they operate in relation to micro- and macro-dynamics resemble some archetypical behavioral patterns conceptualized as institutional traps (Lebel et al. 2011).

According to Polterovich (2008), institutional traps are basically inefficient yet stable norms of behavior. Institutional traps are supported and reinforced by mechanisms of coordination, learning, linkage, and cultural inertia. The acceleration of economic growth, systemic crisis, the evolution of some cultural characteristics, and the development of civil society may result in breaking out of institutional traps (Polterovich 2008). Hence, within the field of SES resilience and transition studies, motivated by the possibility of breaking out of traps, understanding these traps from the stand-point of systems modeling, especially through visualizations such as the now almost ubiquitous ball and cup diagrams and stability landscapes, has become de rigueur.

Unquestionably, these visualizations have contributed in important ways to our collective understanding of SES, and to better illustrating not only traps, but also possibilities for escaping or avoiding them. We do not intend here to diminish the value of these important initial contributions, rather, our hope is to creatively and somewhat critically approach them for the purposes of expanding their explanatory utility, to acknowledge both limits to as well new frontiers in that explanatory utility. In so doing, we must state clearly that we understand the nuances between metaphors and models, and the complexity of their use in scientific discourse (for an excellent review of this subject, see Kretzenbacher 2003), and that in the process of proposing novel perspectives on traps in social-ecological systems, we may fall into traps of our own making. We take this risk happily, confident that the contribution outweighs the consternation, especially if such risks lead to a wider discussion of traps and how we conceive of their existence, their emergence, and their ability to be mitigated, avoided, or deconstructed entirely.

\section{Understanding social-ecological systems via heuristics}

By now, most scholars are familiar with some of the most ubiquitous heuristic visualizations arising out of SES resilience thinking, to include the adaptive cycle and threshold diagrams. Perhaps because of their general explanatory power, these evocative visualizations have in some circles come to symbolize the field itself (see the stylized infinity loop of the Resilience Alliance logo at http://www.resalliance.org/). Yet, even some of the originators of these heuristic visualizations have worried about their overuse, or about efforts to "squeeze everything" into the adaptive cycle or related models (Lance Gunderson and C. S. Holling, personal conversations).

Similarly, we have observed the proliferation of ball and cup type heuristic visualizations, and these visualizations have been productive in assisting researchers to better understand system states. However, little has been written about the limitations of these heuristics, or the implications of their application (or misapplication) in the fast-moving world of transdisciplinary research and theory. Our main point is that there may be traps within traps, and traps that lead to traps. The conceptualization and visual representation of such nested understandings has yet to be fully appreciated among scholars of resilience and sustainability science. In this special feature, we hope to contribute some new theoretical and empirical perspectives on traps that complement existing heuristics. The motivation is that for those involved in planning and governing towards avoiding these traps, there is a prerequisite skill; knowing how to recognize a trap before falling in. Therefore, in this introductory piece, we briefly review the literature on traps as currently described, followed by a synopsis of the contents of the special feature. 


\section{Traps $^{3}$}

Human actions are believed to affect feedbacks and drivers in social-ecological systems, which can lead to regime shifts (see Stockholm Resilience Center Research Insight \#2 at http://www.stockholmresilience.org/21/news-events/ research-insights/insights/2-28-2012-insight-2-regime-shifts. html). Scholars (See Stockholm Resilience Center Research Insight \#5 at http://www.stockholmresilience.org/download/ 18.3e9bddec1373daf16fa43c/INsights_Social-ecological+ traps_111108-2.pdf) have pointed out that changes such as this may alter ecosystem capacity to generate services on which human wellbeing depends, and this in turn may trigger societal responses. Therefore, recognition of these interactions reveals (or reinforces the already known but oft overlooked reality) that the dynamics of social and ecological systems are inextricably linked. These linkages create possibilities where human actors and institutions interact with other ecological dynamics and unwittingly lock development into a vulnerable pathway. In other cases, interactions reinforce the resilience of an already undesirable social-ecological state. These situations can be conceptualized as social-ecological traps (Kretzenbacher 2003).

Following from the work of the Stockholm Resilience Center mentioned above, resilience scholars describe a social-ecological trap as a case where social and ecological feedbacks mutually reinforce one another and maintain or drive a social-ecological system towards an undesirable state. Social-ecological traps are therefore difficult to escape and incremental change will generally be insufficient to break out of such traps (Enfors et al. 2008; Steneck et al. 2011). Importantly, social-ecological traps are similar to but not synonymous with poverty and rigidity traps that have primarily been described as a social phenomenon detached from ecosystems and how their dynamics feed into, are shaped by and affect social processes (cf Carpenter and Brock 2008). Social-ecological traps also share characteristics with studies of the pathology of natural resource management (e.g., Holling and Meffe 1996; Huitric 2005; Sterner et al. 2006) and sunk costs (Janssen and Scheffer 2004; Costanza et al. 2007).

Persistent poverty increases likelihood of succumbing to social-ecological traps. Without alternative income sources, declining revenues from a resource exacerbates poverty (Cinner 2011) as the impoverished are least likely to be able to change their livelihood (Cinner et al. 2009).

\footnotetext{
3 The genesis of this Special Feature on Traps is in part a result of the Stockholm Resilience Center's publication of their synthetic Research Insights, specifically Insight \#2 and \#5. This section of the introduction to the Special Feature thus follows these Research Insights closely, in order to provide appropriate background and context for the advancement of thinking that these insights initiated.
}

Potential for some actors to experience financial rewards can push social-ecological systems toward ever more impoverished and vulnerable states. Because of the high value of a natural resource, stakeholders and managers may be handicapped by a "blind-spot" regarding risks of unexpected sudden decline and associated social-ecological consequences (Steneck et al. 2011). And more well-off communities with profitable markets and government support may be less willing to change their livelihoods if resources decline (Daw et al. 2012). Traps of this nature are often obscured by technological advancements, exploitation of species at lower trophic levels, subsidies, and trade (Huitric 2005; Berkes et al. 2006; Crépin 2007; Thyresson et al. 2011). Yet near-term economic opportunities and masking effects impede or prevent long-term commitments to impede or reverse social-ecological degradation (Deutsch et al. 2007; Nyström et al. 2012).

Rigidity traps occur in social-ecological systems when institutions become highly connected, self-reinforcing, and inflexible (Gunderson and Holling 2002). We explicitly include higher education and research institutions. Poverty traps (Azariadis and Stachurski 2005; Bowles et al. 2006; Carter and Barrett 2006; Barrett et al. 2011), with particular emphasis on non-monetary impoverishment traps, distinct from rigidity traps, represent a situation in which people are impoverished by circumstances beyond their immediate control (Bowles et al. 2006). Thresholds, or tipping points, indicate regime shifts in social-ecological systems and often imply or indicate "traps," especially when we visualize traps in terms of multiple domains in stability landscape models (Herrfahrdt-Pähle and Pahl-Wostl 2012).

Carpenter and Brock (2008) emphasize the changing nature of traps in their efforts to model adaptive capacity. These scholars argue that traps represent persistent maladaptive states, and that the conditions that lead to rigidity or poverty arise in opposite phases of the adaptive cycle. Rigidity can set in when connectivity and potential have increased, while adaptive capacity has atrophied.

At the other end of the cycle, when connectivity or potential are low, impoverishment (poverty traps) can result. This is particularly evident in post-conflict and postdisaster contexts (Spring et al. 2014; Tidball et al. 2014) We take this notion of impoverishment to include multiple capitals, in addition to monetary, and expand upon this notion herein.

\section{Lenses to expand the understanding of traps in social-ecological systems}

The authors in this special feature take a constructive critical approach via novel conceptual and empirical observations on traps, motivated by the existence of contested interpretations of traps among both scholars and lay 


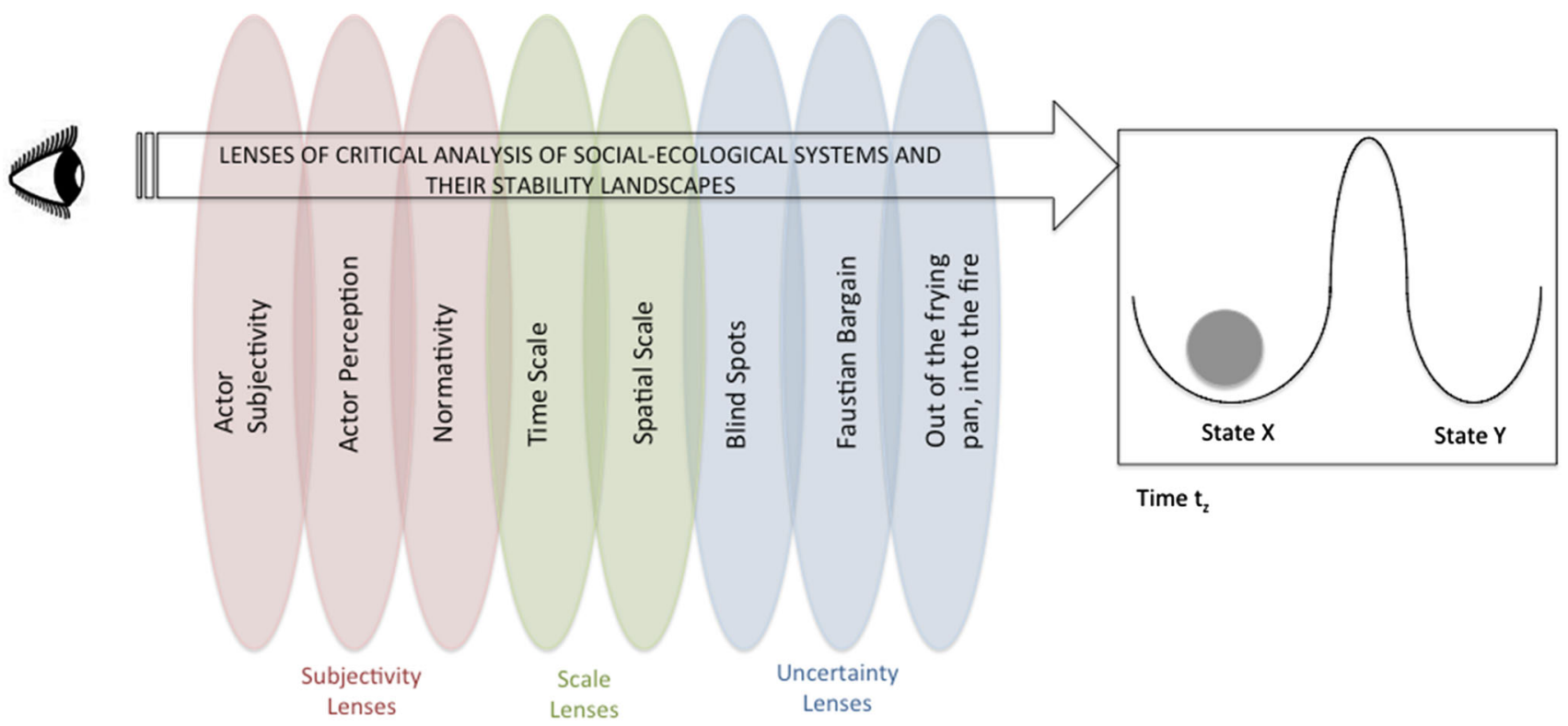

Fig. 1 Proposed lenses to explore social-ecological system traps

persons and the landscapes within which they are described. Building on the work of the participants of the Resilience 2014 Session 56 "Tips or traps? Advancing Understanding to Steer Clear of Impoverishment Traps and Tipping Points" who mused about various "lenses" with which to see traps (see Fig. 1), the authors of this special feature ask "Can we surface qualitatively new types of traps? Or, are all traps describing 'shades' of the two archetypical traps (rigidity and poverty) already well known in the literature? With this in mind, but not decided, the authors herein aim to bring new insights and knowledge to the concept of traps from diverse perspectives while remaining constructively critical of the concept itself: examining the subjectivity of traps, issues of scale, and related unintended consequences.

\section{Contributions}

The contributions of the special feature point out that there is space for theoretical plurality within the traps discourse in social-ecological systems. The contributions of both Tidball and Stedman offer views from the agency perspective considering motives, emotions, identity and interests, a perspective perhaps overlooked in earlier work on traps that remains ontologically and epistemologically at a systems' level perspective. Kroeneberg and Huemback offer an economic perspective to the issue, breaking the 'taboo' on economic ideas for social-ecological systems' resilience. These provide a ground for future theorization regarding the theme of persistence and how it relates to governance for sustainability in social-ecological systems.
The special feature begins with a paper by Tidball (2016). The author argues that, given the theorization that human action often predicates or initiates the series of cascading affects that determine the presence of, and perhaps the effectiveness of, social-ecological traps, we must better understand what drives human action in this context. The author asks what logic, assumptions, decisions, worldviews, and other processes are implicated in this configuration? He works at this question by interrogating the concepts of ecological identity and the problems of anthropocentricism, human exceptionalism, and human exemptionalism, and then introduces the term ecological disenfranchisement. Building upon this, the author invokes Horn's logic and dialectical traps as a lens for understanding human roles and the prevalence of issues with ecological identities, within social-ecological traps. He concludes that efforts to either understand social-ecological traps or navigate away or out of them must first take stock of the human logical traps that actors within the systems are influenced by, and that influence the large systems(s).

Our second paper is that of Boonstra et al. (2016). The authors use a series of cases to introduce three interrelated concepts: motivations, abilities, and opportunities to help theorize the variety of human responses to trap situations.

Moving from the cognitive individual level and smallscale community level to the more broadly social structural level, the third paper of the special feature is by Stedman (2016). The author contends that constructs such as system identity, stability and changes (tips, transitions, transformations from one identity to another), are subjectively perceived, and acted upon by the social actors that occupy these systems, but that this relative lack of recognition of 
subjectivity has become a "rigidity trap" for Social-Ecological Systems and sustainability scholars. Sense of place theory, which emphasizes the creation of meaning as systematically distributed throughout society, is offered as a mechanism for helping SES researchers more fully engage subjectivity.

Our fourth paper by Kronenberg and Hubacek (2016) builds upon the social science of economics to challenge perspectives. The authors put forward an ecosystem service curse hypothesis that points to counterintuitive negative development outcomes for countries and regions rich in ecosystem services. The social and economic problems that they depict in many Payments for Ecosystem Services schemes reflect the persistence of maladaptive states (traps) in pursuit of sustainability, they argue.

The fifth paper of the special feature by Nair and Howlett (2016) addresses policy and management issues at larger organizational scales. The authors point out that even when a policy may be effective in the short-term, changes in problem or policy contexts may render it ineffective over time. The design of 'robust' policies, meaning those which are able to self-adjust to linear changes in their environment can be contrasted with 'resilient' ones which are able to adjust not only to linear but also non-linear shifts in their contexts. With this in mind, they explore three strategies to address policy traps due to climate change.

The sixth paper by Enqvist et al. (2016) concludes the special feature on a hopeful note. The authors argue that social movements can be an important source of change in trapped social-ecological systems. Through a case study of civic engagement, they show that ecological restorations have the potential to counteract trap mechanisms by restoring ecological functions.

\section{Conclusion}

This special feature contributes to Sustainability Science's efforts to probe interactions between global, social, and human systems, the complex mechanisms that lead to degradation of these systems, and concomitant risks to human wellbeing. The proposed "traps" special feature presents a unique, novel, and transdisciplinary effort to simultaneously understand phenomena and solve problems, such as uncertainty and application of the precautionary principle, the co-evolution of knowledge and recognition of problems, and trade-offs between global and local problem solving.

We acknowledge that our societies are far from the endstate referenced as sustainability. The cascading crisesenvironmental, financial, political, and social-create a moment in history that scientists, policy makers, and corporate actors either consider as windows of opportunity or as situations of entrapment. This on-going tension can be enlightened with the concept of "traps," especially by unraveling how traps are understood, perceived and what sustains them. The discussion on traps in social-ecological-technological systems will advance sustainability science by creating new meaning and deepening the thinking on what inhibits our societies from escaping unsustainability traps, by bringing interdisciplinary perspectives from social sciences into the sustainability debate and also by bridging multiple scholarships that actively address the sustainability debate.

Acknowledgments We wish to acknowledge Åsa Norrman and Moira Tidball. Without their patience and hospitality, the Karklö Group would have been considerably less fortified and productive. We also want to thank Richard Stedman for his critical and constructive comments of an earlier version of this introductory editorial piece as well as Erik Andersson and Maria Tengö for their contributions to the theme of the special feature and support to the Karklö Group.

\section{References}

Azariadis C, Stachurski J (2005) Poverty traps. In: Aghion P, Durlauf $\mathrm{SN}$ (eds) Handbook of economic growth. Elsevier, Amsterdam

Barrett CB, Travis AJ, Dasgupta P (2011) On biodiversity conservation and poverty traps. Proc Natl Acad Sci 108(34):13907-13912

Berkes F, Hughes TP, Steneck RS, Wilson JA, Bellwood DR, Crona B, Folke C, Gunderson LH, Leslie HM, Norberg J, Nyström M, Olsson P, Österblom H, Scheffer M, Worm B (2006) Globalization, roving bandits, and marine resources. Science 311:1557-1558

Boonstra WJ, de Boer FW (2014) The historical dynamics of socialecological traps. Ambio 43(3):260-274

Boonstra WJ, Björkvik E, Haider JL, Masterson V (2016) Human responses to social-ecological traps. Sustain Sci. doi:10.1007/ s11625-016-0397-x

Bowles S, Durlauf SN, Hoff K (eds) (2006) Poverty Traps. Princeton University Press, Princeton

Carpenter SR, Brock WA (2008) Adaptive capacity and traps. Ecol Soc 13(2):40

Carter MR, Barrett CB (2006) The economics of poverty traps and persistent poverty: an asset-based approach. J Dev Stud 42:178-199

Cinner JE (2011) Social-ecological traps in reef fisheries. Glob Environ Change 21(3):835-839

Cinner JE, Daw TM, McClanahan TR (2009) Socioeconomic factors that affect artisanal fishers' readiness to exit a declining fishery. Conserv Biol 23:124-130

Costanza R, Graumlich L, Steffen W, Crumley C, Dearing J, Hibbard K, Leemans R, Redman C, Schimel D (2007) Sustainability or collapse: what can we learn from integrating the history of humans and the rest of nature? Ambio 36:522-527

Crépin AS (2007) Using fast and slow processes to manage resources with thresholds. Environ Resour Econ 36:191-213

Daw TM, Cinner JE, McClanahan TR, Brown K, Stead SM, et al (2012) To fish or not to fish: factors at multiple scales affecting artisanal fishers' readiness to exit a declining fishery. PLoS ONE 7(2):e31460. doi:10.1371/journal.pone.0031460 
Deutsch L, Gräslund S, Folke C, Huitric M, Kautsky N, Troell M, Lebel L (2007) Feeding aquaculture growth through globalization: exploitation of marine ecosystems for fishmeal. Glob Environ Change 17:238-249

Enfors E, Gordon L, Peterson G, Bossio D (2008) Making investments in dryland development work: Participatory scenario planning in the Makanya catchment Tanzania. Ecol Soc 13. http://www.ecologyandsociety.org/vol13/iss2/art42/

Enqvist J, Tengo M, Boonstra WJ (2016) Against the current: rewiring rigidity trap dynamics in urban water governance through civic engagement. Sustain Sci. doi:10.1007/s11625-016-0377-1

Gunderson LH, Holling CS (eds) (2002) Panarchy: understanding transformations in human and natural systems. Island Press, Washington

Herrfahrdt-Pähle E, Pahl-Wostl C (2012) Continuity and change in social-ecological systems: the role of institutional resilience. Ecol Soc 17(2):8

Holling CS, Meffe GK (1996) Command and control and the pathology of natural resource management. Conserv Biol 10(2):328-337

Huitric M (2005) Lobster and conch fisheries of Belize: a history of sequential exploitation. Ecol Soc 10(1):21

Janssen MA, Scheffer M (2004) Overexploitation of renewable resources by ancient societies and the role of sunk-cost effects. Ecol Soc 9(1):6

Kretzenbacher HL (2003) The aesthetics and heuristics of analogy: model and metaphor in chemical communication. HYLE Int $\mathrm{J}$ Philos Chem 9(2):191-218

Kronenberg J, Hubacek K (2016) From poverty trap to ecosystem service curse. Sustain Sci. doi:10.1007/s11625-016-0370-8

Lebel L, Manuta JB, Garden P (2011) Institutional traps and vulnerability to changes in climate and flood regimes in Thailand. Reg Environ Change 11(1):45-58

Nair S, Howlett M (2016) From robustness to resilience: avoiding policy traps in the long term. Sustain Sci. doi:10.1007/s11625$016-0387-\mathrm{z}$
Nyström M, Norström AV, Blenckner T, de la Torre-Castro M, Eklöf JS, Folke C, Österblom H, Steneck RS, Thyresson M, Troell M (2012) confronting feedbacks of degraded marine ecosystems. Ecosystems 15(5):695-710

Polterovich V (2008) Institutional trap. In: Durlauf SN, Blume LE (eds) The new Palgrave dictionary of economics online. Palgrave Macmillan, New York

Spring ÚO, Brauch HG, Tidball KG (2014) Expanding peace ecology: peace, security, sustainability, equiuty, and gender. Springer, New York

Stedman RC (2016) Subjectivity and social-ecological systems: a rigidity trap (and sense of place as a way out). Sustain Sci. doi:10.1007/s11625-016-0388-y

Steneck RS, Hughes TP, Cinner JE, Adger WN, Arnold SN, Berkes F, Boudreau SA, Brown K, Folke C, Gunderson LH, Olsson P, Scheffer M, Stephenson E, Walker B, Wilson J, Worm B (2011) Creation of a gilded trap by the high economic value of the Maine lobster fishery. Conserv Biol 25:904-912

Sterner T, Troell M, Vincent J, Aniyar S, Barrett S, Brock W, Carpenter SR, Chopra K, Ehrlich P, Hoel M, Levin SA, Mäler K-G, Norberg J, Pihl L, Söderqvist T, Wilen J, Xepapadeas A (2006) Quick fixes for the environment: part of the solution or part of the problem. Environment 40(10):20-27

Thyresson M, Nyström M, Crona B (2011) Trading with resilience: parrotfish trade and the exploitation of key-ecosystem processes in coral reefs. Coast Manag 39(4):396-411

Tidball KG (2016) Traps in and of our minds: relationships between human logic, dialectical traps and social-ecological traps. Sustain Sci. doi:10.1007/s11625-016-0396-y

Tidball KG, Weinstein ED, Krasny ME (2014) Syntheis and conclusions: applying greening in red zones. In: Tidball KG, Krasny ME (eds) Greening in the red zone: disaster, resilience, and community greening. Springer, New York, pp 451-486 